\title{
Importance of mapping the external environment in image-guided video-assisted thoracoscopic surgery
}

\author{
Sai Yendamuri, MBBS, and Todd L. Demmy, MD, FACS
}

\author{
From the Department of Thoracic Surgery, Roswell Park Cancer Institute, Buffalo, NY. \\ Disclosures: Authors have nothing to disclose with regard to commercial support. \\ Received for publication Dec 5, 2017; accepted for publication Dec 18, 2017; available ahead of print Jan 17, \\ 2018. \\ Address for reprints: Todd L. Demmy, MD, FACS, Department of Thoracic Surgery, Roswell Park Cancer Insti- \\ tute, Elm and Carlton Sts, Buffalo, NY 14263 (E-mail: todd.demmy@ roswellpark.org). \\ J Thorac Cardiovasc Surg 2018;155:1833 \\ $0022-5223 / \$ 36.00$ \\ Copyright (C) 2017 by The American Association for Thoracic Surgery \\ https://doi.org/10.1016/j.jtcvs.2017.12.070
}

As hybrid operating rooms (ORs) multiply, real-time axial imaging is becoming more accessible for thoracic surgeons to enhance transcatheter cardiac valve placement and other cardiovascular interventional procedures. This promises to complement such technology as navigational bronchoscopy and possibly replace preoperative computed tomography (CT) for the purpose of localizing lung nodules. In this issue of the Journal, Hseih and colleagues ${ }^{1}$ describe their learning curve with the use of a cone beam CT in their hybrid OR to transition from a 2-step localization procedure to true intraoperative image-guided localization. We have attempted to use a similar portable gantry technology (O-arm; Medtronic, Minneapolis, Minn) with little success, because of difficulty in positioning the target.

The physics of cone beam imaging yields optimal resolution when the target is centered, making the O-arm useful for central spine and neurosurgical procedures. A peripheral lung tumor is outside of this central location especially when the patient is in a lateral decubitus position. By eliminating the bulk of the OR table base, an orthopedic frame system yields a bit more flexibility by allowing the contralateral torso to be shifted lower in the spin field so that the target becomes more centered; however, the system is unwieldy and does not allow for table flexion, which is preferred by surgeons in thoracic procedures. The hybrid system available to the authors seems to eliminate some of these barriers, although they still needed to tilt the patient to bring the target into optimal imaging locations. Although several different approaches have been described to accomplish this task, what is unique about the authors' work is the number of practical tips provided for the audience to enhance the utility and temper the learning curve associated with its adoption.

Over 30 cases, the authors lay out the mapping of the external environment required to make full use of the complex open arc geometry of the $\mathrm{C}$ arm cone beam used.

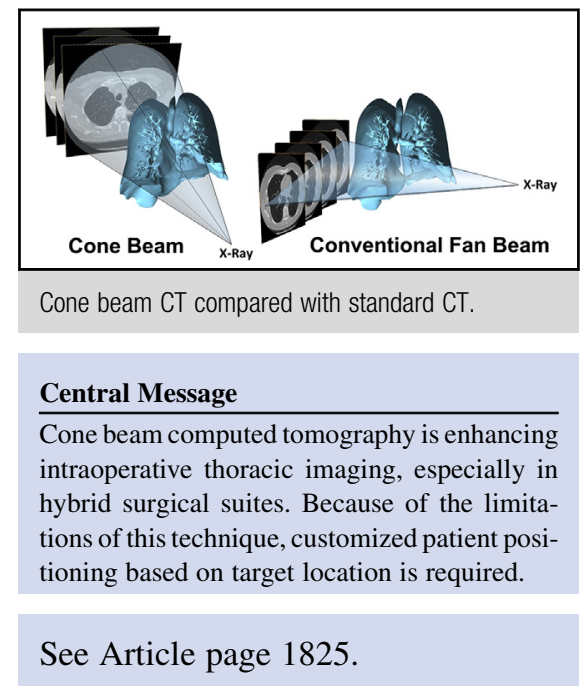

Because of this geometry, for certain lesions, the CT must be placed counterintuitively to obtain the best field of view not only for the lesion, but also for the point of entry of the localizer. This is summarized in a simple schematic supplied by the authors. In addition, the authors do away with completely supine or prone positions and instead use a primary lateral decubitus position with semiprone or semisupine modifications to achieve an optimal field of view. This enables them to accomplish the localization and the surgery without repositioning the patient.

To the extent that the number of cases performed by the authors does not enable a true measure of the learning curve by a formal threshold analysis, the title is misleading and does not represent the full import of the work presented. In an era of increasing process flow optimization and hybrid OR suites, this report is a useful addition to the literature in both areas. Given that such imaging technology inevitably improves and becomes ubiquitous, it is likely that we will be able to use it as we do fluoroscopy today, warranting its incorporation into current practice.

\section{Reference}

1. Hsieh M-J, Wen C-T, Fang H-Y, We Y-W, Lin CC, Chao Y-K. Learning curve of image-guided video-assisted thoracoscopic surgery for small pulmonary nodules: a prospective analysis of thirty initial patients. J Thorac Cardiovasc Surg. 2018; 155:1825-32.e1. 